\title{
Duplex Ultrasound Versus Computed Tomography For Follow Up Of Complications after Evar With Nellix Endograft: First Clinical Experience.
}

\author{
Natalija Ezite **, ***, Janis Savlovskis **, ***, Marcis Gedins *, **, Kaspars Kisis *, ****, Polina Dombure *, ****, Dainis \\ Krievins *, *** \\ * Department of Vascular Surgery, Pauls Stradins Clinical University Hospital, Riga, Latvia \\ ** Department of Radiology, Pauls Stradins Clinical University Hospital, Riga, Latvia \\ *** University of Latvia, Riga, Latvia \\ **** Riga Stradins University, Riga, Latvia
}

\section{Summary}

Introduction. Contrast-enhanced computed tomography (CT) has become the 'gold-standard' imaging modality for surveillance following EVAR $(2,20)$. However repeated CT is related to increased cost, risk of contrast nephropathy and radiation exposure. Duplex ultrasound (DUS) is a less invasive but considered less accurate method than CT.

Aim of the study. The aim of this study was to determine the diagnostic accuracy of both imaging modalities for detection of complications in post-EVAR patients where the new generation sac-sealing endograft was used and to compare cost-effectiveness and sensitivity of both imaging modalities.

Methods. Analysis of 23 post-EVAR patients with implantation of new generation sac-sealing endograft device (Nellix@, Endologix, USA) was performed, making a comparison of CT and DUS. Contrast-enhanced computed tomography was taken as the 'goldstandard' investigation. DUS was compared to CT for analysis of sensitivity, post-imaging complications and cost-effectiveness. Statistical analysis of data was performed using v19.0 SPSS software (IBM).

Results. Analysis of CT and DUS studies compared in 23 patients. Both imaging modalities can detect AAA sac dimensions, endoleaks, and graft patency. The cost difference between two imaging techniques is substantial. Our results demonstrate that DUS surveillance during follow-up after EVAR where new generation sac-sealing endograft is used can accurately detect aneurysm size, endoleaks, graft deformations and stenotic or kinked graft limbs while lowering the overall costs of surveillance and eliminating CT related radiation and nephrotoxicity.

Conclusion. CT and DUS imaging can both detect AAA sac dimensions, endoleaks, and graft patency. The cost difference between the two imaging techniques is substantial. Our results demonstrate that in post-EVAR patients where new-generation sac-sealing endograft was deployed DUS surveillance performed by experienced radiologist can accurately detect aneurysm size, endoleaks, graft deformations and stenotic or kinked graft limbs while lowering the overall costs of surveillance and avoiding CT-related complications.

Key words: abdominal aortic aneurysm; endovascular aneurysm repair; aneurysm sac sealing device; duplex ultrasound; computed tomography.

\section{INTRODUCTION}

Endovascular aneurysm repair (EVAR) was first described in 1991 and is associated with a lower short- and midterm morbidity and mortality $(13,14)$. However, such complications as endoleaks, endograft migration and deformations require life-long post-EVAR surveillance. The importance of these long-term risks is highlighted by recently presented data from the DREAM trial that shows greater 5-year post-discharge mortality in patients treated by EVAR compared with those undergoing open aneurysm repair (14). Endoleak in particular carries great significance, as it is predictive of post-EVAR rupture (27), and therefore, post-EVAR endoleak surveillance has become mandatory. At present contrast-enhanced spiral computed tomography (CT) angiography with specialized 3D reconstruction is considered as the gold standard for endoleak surveillance $(1,20)$. CT angiography is efficient in defining the anatomy of aneurysm sac, detection of endoleak and its classification but is associated with adverse factors including high dose of radiation, contrast nephrotoxicity and associated with contrast allergies, and high cost (5, $6,23,26)$. However upon development of new device technologies, and in particular introduction of new generation sac-sealing endograft device (12), DUS may be a good alternative to CT for the follow-up of EVAR patients. This modality is less expensive and does not carry the risks associated with ionizing radiation or contrast induced nephrotoxicity, however the sensitivity and specificity of DUS in comparison to CT in post-EVAR follow-up have been argued.,

\section{AIM OF THE STUDY}

The aim of this research paper is to update the sensitivity and specificity values of DUS in comparison to CT for patient follow-up after EVAR with new generation sacsealing endograft. 


\section{MATERIALS AND METHODS}

Nellix endograft is a new endoluminal sac-sealing device, which is designed to treat aortic aneurysms by obliterating the aneurysm sac, thus eliminating the potential endoleak space, while maintaining normal blood flow to the lower extremities. The endograft bloodflow lumens are supported with the balloon-expandable endoframes surrounded by the polymer-filled endobags, without the need for proximal and distal fixation. Full details of the device and clinical procedure are described in our previous reports $(12,17,18)$.

23 post-EVAR (Nellix ${ }^{\circledR}$, Endologix, USA) patients have been prospectively followed-up upon discharge, at six, twelve and twenty-four months at Pauls Stradins Clinical University Hospital (Riga, Latvia). The approval of ethical committee for the study was obtained and all patients have signed informed consent forms.

Two imaging modalities were used for post-procedural follow-up: DUS (Phillips iU22 xMatrix with multifrequence probe $2-4 \mathrm{MHz}$ ) with multifrequency probe $(2-4,12 \mathrm{MHz}$ ) and 64-layer CT (General Electric LightSpeed). DUS protocol included the assessment of AAA external diameter measurements in B-mode before and after EVAR in AP and transversal planes. Colour Doppler (spectral analysis, flow velocity) was used for stent graft, proximal neck and iliac arteries assessment. Contrast-enhanced computed tomography was taken as the 'gold-standard' investigation. Standard duplex ultrasound was compared to CT. Analysis was performed by two experienced radiologists participating in the trial. Statistical analysis was done using SSPS software, v19.0 (IBM).

\section{RESULTS}

All 23 post-EVAR patients have been prospectively followed up using DUS and CT imaging modalities. Four patients have been followed up for the period of six months, seven patients for the period of twelve months and twelve patients for the period of twentyfour months.

Measurements compared between CT and DUS are provided in Table 1. All separately analysed parameters are provided in Figures 1-7. AAA size correlation between DUS and CT in dynamical follow-up has provided good correlation between two imaging modalities ( $\mathrm{r} 2=0.9379, \mathrm{r}=0.9684, \mathrm{p}<0.001$ ) (Figure 1) with DUS taking considerably shorter time of assessment ( $22 \pm 8 \mathrm{~min}$, CT $94 \pm 28 \mathrm{~min} ; \mathrm{p}<0.001)$.

In one patient both DUS and CT detected type 2 endoleak on early follow-up. Another patient had a graft stenosis more than $50 \%$ detected by both DUS and CT, however DUS allowed more precise values by flow velocity determination.

DUS was found to be a considerably more cost-effective method (DUS 18.50 LVL and CT 146.00 LVL).

\section{DISCUSSION}

Although previous authors have compared DUS and CT scans for surveillance after EVAR, CT scan remains the 'gold standard' for assessment of aneurysmal diameter, detection of endoleak, and graft patency (2, 19, 20, 22). The benefits of CT as an imaging modality compared with DUS imaging include that it is highly reproducible, less influenced by body habitus, and offers faster image acquisition. However, among the limitations of CT are repeated radiation exposure, potential contrast-related complications, including allergy and renal insufficiency, and high costs $(22,23,26)$.

AAA size reduction over time has been used as a surrogate marker for successful exclusion, thrombosis of the aneurysm sac, and decreased risk of rupture $(23,31)$. Many authors have shown that CT and DUS imaging are equivalent for measuring AAA sac size after $\operatorname{EVAR}(2,19,20)$.

Endoleak detection by DUS imaging in our study was as or more accurate than by CT, which is similar to the results provided by other authors $(1,27)$. Moreover, we believe that DUS imaging is more accurate than CT in detecting endograft related complications such as migration, deformation, kinking, and stenosis. Colourflow images give physiologic as well as anatomic information that CT does not. We believe that DUS imaging can almost always accurately determine if structural defects are causing a flow-related problem and graft migration.

It was shown in previous studies that cost savings is substantial when DUS imaging alone is used for midterm and long-term follow-up versus the accepted approach that requires multiple CT scans $(5,6,7,22$, 24). Kim et al estimated that current reimbursement for long-term EVAR surveillance and secondary procedures using traditional protocols average a net loss of \$2235 per patient (16). Although hospital system charges vary by institution, in the setting of Latvian challenging economy the saving of 127.50 LVL (respectively 182.14 Euro). Inflation and decreasing reimbursements over time affect cost and charges, which makes a true cost analysis difficult. We performed our cost analysis using 2008 health care system charges to reflect the potential cost savings for the current economic climate and with today's health care system, which is significantly different than that of 1998, when our study began. Regardless, the cost savings are substantial when CT and DUS are compared for EVAR surveillance.

This study has some potential weaknesses. DUS imaging is more operator-dependent and has more interobserver variability than CT and is significantly affected by the patient's body habitus and fasting status. DUS imaging with contrast may prove to be especially useful for obese patients but is not necessarily any better in most patients, especially considering the extra cost and more difficult technique required to use this method.

The accuracy of DUS imaging to detect post-EVAR complications may vary depending on different graft designs, however, in our experience with new generation sac-sealing endograft we found that DUS is a better or at least as sensitive as CT in post-EVAR followup. 


\section{CONCLUSIONS}

Although DUS is often used to augment CT scanning in post-EVAR follow-up, this evidence suggests that it is suitable for sole use in graft complications detection after EVAR. Our study confirms that DUS is a safe and sensitive modality for endoleak detection, graft migration and deformations detections, potentially obviating the need for patient exposure to high radiation doses and nephrotoxic agents in recurrent CT imaging. Further studies are required to understand whether DUS can completely replace CT imaging in the follow-up of patients after EVAR with new generation sac-sealing device.

\section{Conflict of interest: None}

\section{REFERENCES}

1. Akro FR, Filas KA, Siedel SA, Johnson BL, Drake AR, Fogarty TJ, et al. Intrasac flow velocities predict sealing of type II endoleaks after endovascular abdominal aneurysm repair // J Vasc Surg, 2003; 37:8-15.

2. Badri H, El Haddad M, Ashour H, Nice C, Timmons G, Bhattacharya V. Duplex ultrasound scanning (DUS) versus computed tomography angiography (CTA) in the follow-up after EVAR // Angiology, 2010 Feb; 61(2):131-6.

3. Bakken AM, Illig KA. Long-term follow-up after endovascular aneurysm repair: is ultrasound alone enough? // Perspect Vasc Surg Endovasc Ther, 2010 Sep; 22(3):145-51.

4. Bargellini I, Cioni R, Napoli V, Petruzzi P, Vignali C, Cicorelli A, Sardella S, Ferrari M, Bartolozzi C. Ultrasonographic surveillance with selective CTA after endovascular repair of abdominal aortic aneurysm // J Endovasc Ther, 2009 Feb;16(1):93104.

5. Beeman BR, Doctor LM, Doerr $\mathrm{K}$, McAfeeBennett S, Dougherty MJ, Calligaro KD. Duplex ultrasound imaging alone is sufficient for midterm endovascular aneurysm repair surveillance: a cost analysis study and prospective comparison with computed tomography scan // J Vasc Surg, 2009 Nov; 50(5):1019-24.

6. Bosch JL, Kaufman JA, Beinfeld MT, Miraude EA, Brewster DC, Gazelle GS. Abdominal aortic aneurysms: cost-effectiveness of elective endovascular and open surgical repair // Radiology, 2002; 225:337-344.

7. Bosch JL, Lester JS, McMahon PM, Beinfeld MT, Halpern EF, Kaufman JA, et al. Hospital costs for elective endovascular and surgical repairs of infrarenal abdominal aortic aneurysms // Radiology, 2001; 220:492-497.

8. Chaer RA, Gushchin A, Rhee R, Marone L, Cho JS, Leers S, Makaroun MS. Duplex ultrasound as the sole long-term surveillance method postendovascular aneurysm repair: a safe alternative for stable aneurysms // J Vasc Surg, 2009 Apr; 49(4):845-9; discussion 849-50.
9. Chisci E, Setacci F, Iacoponi F, de Donato G, Cappelli A, Setacci C. Surveillance imaging modality does not affect detection rate of asymptomatic secondary interventions following EVAR // Eur J Vasc Endovasc Surg, 2012 Mar; 43(3):276-81.

10. Clair DG, Gray B, O'Hara PJ, Ouriel K. An evaluation of the costs to health care institutions of endovascular aortic aneurysm repair // J Vasc Surg, 2000; 32:148-152.

11. Collins JT, Boros MJ, Combs K. Ultrasound surveillance of endovascular aneurysm repair: a safe modality versus computed tomography //Ann Vasc Surg, 2007; 21:671-675.

12. Donayre CE, Zarins CK, Krievins D, Holden A, Hill A, Calderas C, Velez J, White RA. Initial clinical experience with a sac-anchoring endoprosthesis for aortic aneurysm repair // J Vasc Surg, 2011; 53(3):574-582.

13. Prinssen M, Buskens E, Blankensteijn JD; DREAM trial participants. Quality of life endovascular and open AAA repair. Results of a randomised trial // Eur J Vasc Endovasc Surg, 2004 Feb; 27(2):121-7.

14. EVAR trial participants. Endovascular aneurysm repair versus open repair in patients with abdominal aortic aneurysm (EVAR trial 1): randomized controlled trial // Lancet, 2005; 356:2179-2186.

15. Harrison GJ, Oshin OA, Vallabhaneni SR, Brennan JA, Fisher RK, McWilliams RG. Surveillance after EVAR based on duplex ultrasound and abdominal radiography // Eur J Vasc Endovasc Surg, 2011 Aug; 42(2):187-92.

16. Kim JK, Tonnessen BH, Noll RE, Money SR, Sternberg WC. Reimbursement of long-term postplacement costs after endovascular abdominal aortic aneurysm repair // J Vasc Surg, 2008; 48:1390-1395.

17. Kisis K, Krievins D, Naskovica K, Gedins M, Savlovskis J, Ezite N, Lietuvietis E, Zarins K. Quality of life after endovascular abdominal aortic aneurysm repair: Nellix sac-anchoring endoprosthesis versus open repair // Medicina, 2012; 48(6):286-291.

18. Krievins D, Holden A, Savlovskis J, Calderas C, Donayre CE, Moll FL, Katzen B, Zarins CK. EVAR using the Nellix Sac-anchoring endoprosthesis: treatment of favourable and adverse anatomy // Eur J Vasc Endovasc Surg, 201 1; 42(1):38-46.

19. Kranokpiraksa P, Kaufman JA. Follow-up of endovascular aneurysm repair: plain radiography, ultrasound, CT/CT angiography, MR imaging/MR angiography, or what? // J Vasc Interv Radiol, 2008; 19:S27-S36.

20. Karthikesalingam A, Al-Jundi W, Jackson D, Boyle JR, Beard JD, Holt PJ, Thompson MM. Systematic review and meta-analysis of duplex ultrasonography, contrast-enhanced ultrasonography or computed tomography for surveillance after endovascular aneurysm repair // Br J Surg, 2012 Nov; 99(11):1514-23.

21. Manning BJ, O'Neill SM, Haider SN, Colgan MP, Madhavan P, Moore DJ. Duplex ultrasound in 
aneurysm surveillance following endovascular aneurysm repair: a comparison with computed tomography aortography // J Vasc Surg, 2009 Jan; 49(1):60-5.

22. Noll RE, Tonnessen BH, Mannava K, Money SR, Sternbergh CW. Long-term postplacement cost after endovascular aneurysm repair // J Vasc Surg, 2007; 46:9-15.

23. Parfrey PS, Griffiths SM, Barrett BJ, Paul MD, Genge M, Withers J, et al. Contrast materialinduced renal failure in patients with diabetes mellitus, renal insufficiency, or both (A prospective controlled study) // N Engl J Med, 1989; 320:143149.

24. Prinssen M, Wixon CL, Buskens E, Blankensteijn JD. Surveillance after endovascular aneurysm repair: diagnostics, complications, and associated costs // Ann Vasc Surg, 2004; 18:421427.

25. Raman KG, Missig-Carroll N, Richardson $\mathrm{T}$, Muluk SC, Makaroun MS. Color-flow duplex ultrasound scan versus computed tomographic scan in the surveillance of endovascular aneurysm repair // J Vasc Surg, 2003; 38:645-651.

26. Radiation risk: directorate-general for the environment of the European Commission: Referral guidelines for imaging // European Commission, Radiation Protection Report, 2000;118.

27. Schmieder GC, Stout CL, Stokes GK, Parent FN, Panneton JM. Endoleak after endovascular aneurysm repair: duplex ultrasound imaging is better than computed tomography at determining the need for intervention // J Vasc Surg, 2009 Nov; 50(5):1012-8.

28. Sternberg WC, Greenberg RK, Chuter TA, Tonnessen BH. Redefining postoperativesurveillance after endovascular repair: recommendations based on 5-year follow-up in the US Zenith multicenter trial // J Vasc Surg, 2008; 48:278-283.

29. Sun Z. Diagnostic value of color duplex ultrasonography in the follow-up of endovascular repair of abdominal aortic aneurysm // J Vasc Interv Radiol, 2006 May; 17(5):759-64.

30. United Kingdom EVAR Trial investigators, Greenhalgh RM, Brown LC, et al. Endovascular versus open repair of abdominal aortic aneurysm // N Engl J Med, 2010; 362(20):1863-1871.

31. Wolf YG, Johnson BL, Hill BB, Rubin GD, Fogarty TJ, Zarins CK. Duplex ultrasound scanning versus computed tomographic angiography for postoperative evaluation of endovascular abdominal aortic aneurysm repair // J Vasc Surg, 2000; 32:1142-1148.

32. Verhoeven EL, Oikonomou K, Ventin FC, Lerut P, Fernandes E Fernandes R, Mendes Pedro L. Is it time to eliminate CT after EVAR as routine follow-up? // J Cardiovasc Surg (Torino), 2011 Apr; 52(2):193-8. Review.

\section{Address:}

Natalija Ezite,

Department of Radiology,

Pauls Stradins Clinical University Hospital

13 Pilsonu street, LV-1002, Riga, Latvia

Email: ezite.n@gmail.com

Table 1: Measurements compared between CTA and DUS

\begin{tabular}{|l|l|}
\hline \multicolumn{1}{|c|}{ CTA } & \multicolumn{1}{|c|}{ DUS } \\
\hline $\begin{array}{l}\text { Transverse luminal size in } \\
\text { the maximum stent graft } \\
\text { deformation area }\end{array}$ & $\begin{array}{l}\text { Maximal systolic blood } \\
\text { flow (PSV) in the area of } \\
\text { maximum stenosis }\end{array}$ \\
\hline $\begin{array}{l}\text { Luminal stenosis of stent } \\
\text { graft in the maximum } \\
\text { stent graft deformation } \\
\text { area }\end{array}$ & $\begin{array}{l}\text { Spectral blood flow in the } \\
\text { external iliac artery }\end{array}$ \\
\hline $\begin{array}{l}\text { Angular deformation of } \\
\text { the stent graft }\end{array}$ & \\
\hline
\end{tabular}




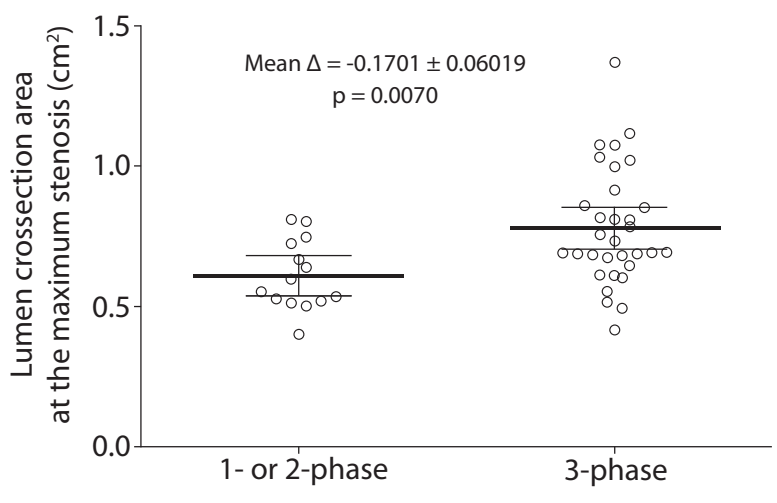

Fig. 1. The analysis showing that patients with 3-phased blood flow had a stent graft lumen approximately $17 \mathrm{~mm}^{2}$ larger than those patients with a changed spectrum

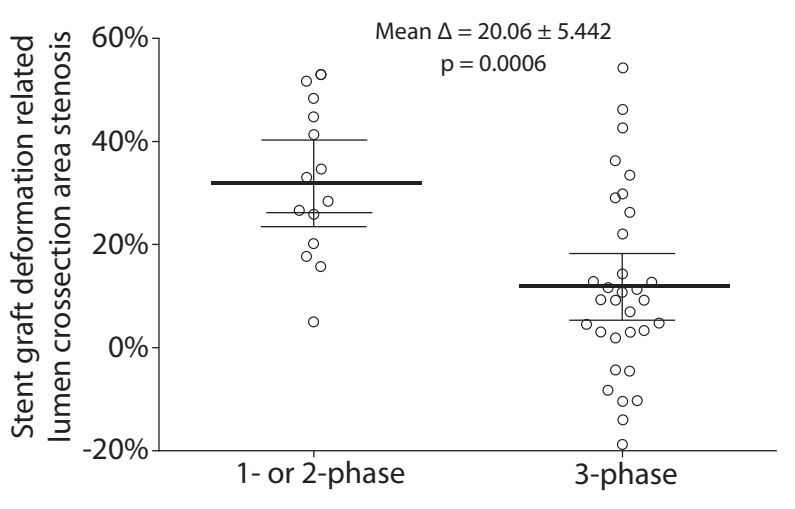

Fig. 2. Patients with unchanged blood flow spectrum had stenosis of stent graft most of the times $<20 \%$. The average difference between registered stent graft stenosis in patients with changed and unchanged blood flow spectrum comprised $20 \%$

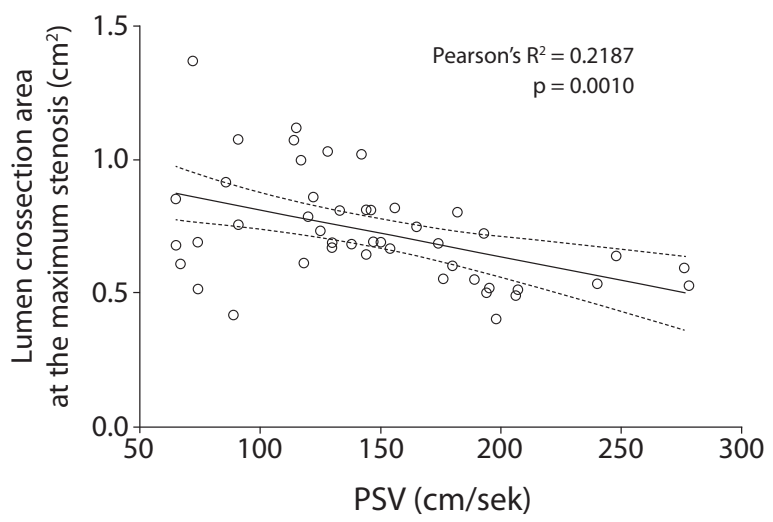

Fig. 4. Correlation between luminal cross-sectional area at the level of maximum stenosis and PSV is weakly expressed. Pearson's correlation coefficient is $\sim 0.22$, however this correlation is statistically significant $(p=0.001)$ 


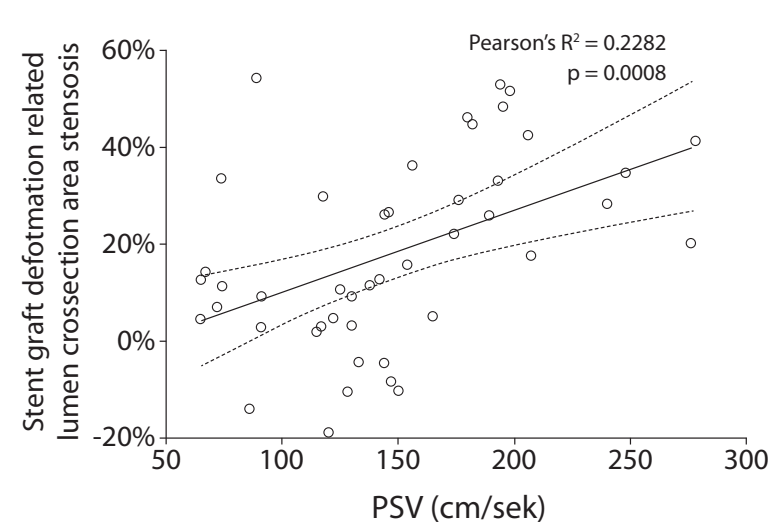

Fig. 5. Similar correlation was found also between cross-sectional stenosis and PSV
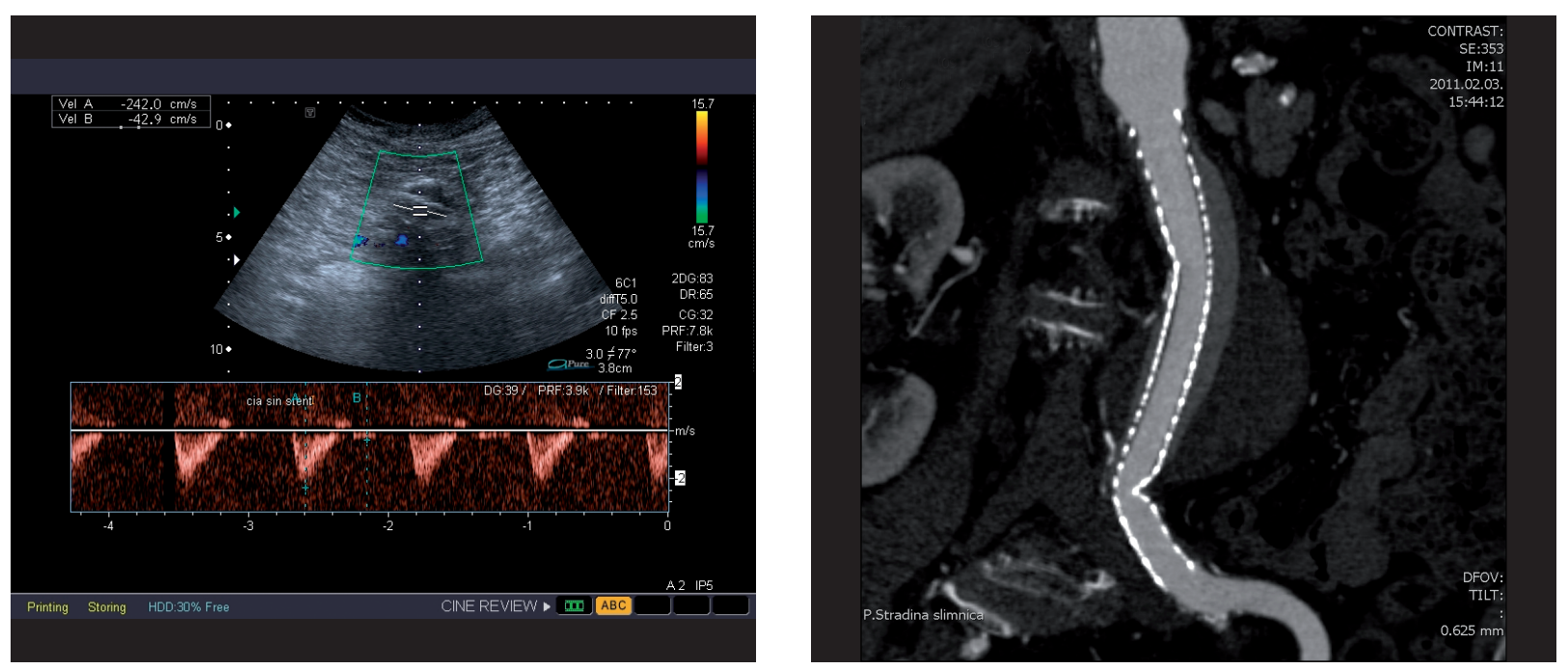

Fig. 6. Correlation of stent graft angular deformation with PSV approximatesd 0.3 with high statistical significance $(p<0.0001)$

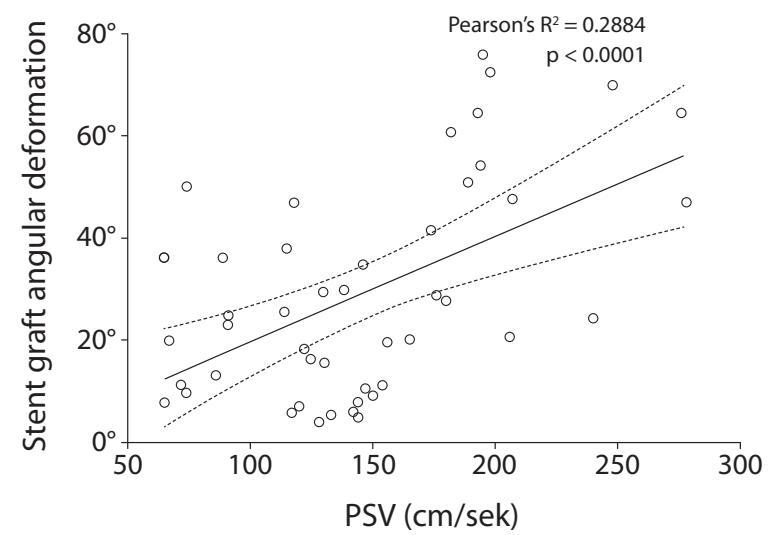

Fig. 7. Patient DUS and CT image in post-EVAR follow up with graft stenosis detected $(242 \mathrm{~cm} / \mathrm{s}$ in DUS equal to approximately $60 \%$ stenosis) 